\title{
Balance impairments in patients with a sub-acute ankle sprain receiving no exercise therapy: A comparative study
}

\author{
Ilona M Punt ${ }^{1-3}$, Stéphane Armand ${ }^{4}$, Jean-Luc Ziltener ${ }^{5}$ and Lara Allet ${ }^{1,2 *}$ \\ ${ }^{1}$ School of Health Sciences, HES-SO University of Applied Sciences and Arts Western Switzerland, Switzerland \\ ${ }^{2}$ Geneva University Hospitals and University of Geneva, Switzerland \\ ${ }^{3}$ Maastricht University, Epidemiology and CAPHRI Research School, Netherlands \\ ${ }^{4}$ Geneva University Hospital and University of Geneva, Willy Taillard Laboratory of Kinesiology, Switzerland \\ ${ }^{5}$ Department of Surgery, Geneva University Hospitals and University of Geneva, Switzerland
}

\begin{abstract}
Aim: To compare single-leg balance performance between subacute ankle sprain patients receiving no exercise therapy and healthy persons.

Methods: Forty-eight subacute ankle sprain patients (age $=34.3 \pm 9.7$ years) and 10 healthy persons (age $=30.1 \pm 4.7$ years) participated in the study. Participants underwent an assessment of body functions and a 30-second single-leg balance test on a force plate under stable and unstable conditions. Center of pressure (COP) range, length and speed in mediolateral (ML) and anteroposterior (AP) directions were calculated.

Results: All healthy persons finished the 30 -second balance test under both conditions. Forty-three patients (90\%; $P=.374)$ were able to complete the test on the stable surface and 38 patients $(79 \% ; P=.125)$ on the unstable surface. Ankle sprain patients showed increased COP AP speed compared to healthy persons for stable conditions $(P=.009)$ and a larger COP AP range for unstable conditions $(P=.001)$. Furthermore, muscle strength in inversion and eversion were correlated to COP performance $(P<.050)$.
\end{abstract}

Conclusion: Specific ankle strength exercises, including muscle strength exercises in the frontal plane, might improve balance performance in ankle sprain patients.

\section{Introduction}

Ankle sprains represent approximately $15 \%$ of all sports-related injuries [1], and the incidence of re-injury of a sprained ankle is $3-34 \%$ during the first year after the initial trauma [2]. Furthermore, up to $74 \%$ of patients who reinjure their ankle have chronic ankle instability, [2] which has a negative influence on daily life activities and sport performance. It is also known that ankle sprains lead to high direct and indirect health care costs $[2,3]$. The high costs and high incidence rates make it necessary to gather comprehensive information on ankle sprain mechanisms and consequences in order to better tailor treatments.

Potential risk factors and mechanisms that contribute to increased ankle sprain recurrence include altered intrinsic body functions, such as decreased proprioception in the ankle ligaments, muscle weakness and limited range of motion, and extrinsic factors such as inappropriate footwear $[2,4]$.

Genthon et al. [5] showed that ankle sprain patients present asymmetric balance in their bipedal stance during the first 10 days after injury. From day 10 to day 30 bipedal balance improved and returned to normal after 30 days [5]. However, the effects of functional deficits may become more evident while balancing on one leg [4,6,7]. A review of McKeon et al. [4] showed that balance performance of the injured ankle was impaired after an acute lateral ankle sprain compared to healthy controls. Although patients significantly improve their postural control (e.g., Center Of Pressure Range, Length And Speed) during the first four weeks after an ankle sprain, [8,9] they frequently experience residual functional deficits (Muscle Strength, Mobility) and impaired postural control after this four-week period $[8,10]$.

It is important to identify residual functional deficits and balance impairments in order to tailor treatments. If clinicians can address these deficits, better prevention of recurrent ankle sprain injuries should be possible. Previous studies assessed such parameters in patients with a history of ankle sprain $[4,11,12]$. However, no study correlated these residual functional deficits with postural balance during the subacute phase (four weeks after the sprain), during which patients could still benefit from a specific treatment.

Therefore, the aim of this study was 1) to assess the relationship between balance performance and individuals' body functions (muscle strength, range of motion, pain); and 2) to compare single-leg balance performance between subacute ankle sprain patients receiving no exercise therapy and healthy persons.

Correspondence to: Lara Allet, Geneva University Hospitals and University of Geneva, Switzerland, E-mail : lara.allet@hcuge.ch

Key words: ankle sprain, subacute phase, muscular strength, joint mobility, postural balance, center of pressure

Received: November 11, 2017; Accepted: December 01, 2017; Published: December 05, 2017 


\section{Materials and methods}

\section{Design}

This is a case-control study comparing ankle sprain patients to healthy controls.

\section{Participants}

Forty-eight subacute lateral ankle sprain patients visiting the emergency department with a grade I or II ankle sprain were consecutively included in the study four weeks after their initial trauma. Ten healthy persons were selected as a convenience sample of students and matched by age, BMI and sex to the ankle sprain patients (Table 1). All participants were aged from 18 to 55 years and had a BMI < 30. Patients were excluded if they had a grade III rupture of the ankle ligament, any neurological, musculoskeletal or other disorders that could influence postural control or if they had a recurrent ankle sprain on the same site within the last 12 months.

Medical ethical approval was obtained (09_116); all participants were informed about the procedures and signed informed consent forms.

\section{Procedures}

The ankle sprain patients were discharged from the emergency department after the physician provided standard instructions regarding rest, ice, compression and elevation (RICE protocol) and pain-free movement for four weeks. In addition, patients received a semirigid Aircast ankle brace during this four-week period.

After four weeks, the ankle sprain patients underwent a clinical examination by an experienced physical therapist during which joint mobility, muscle strength and pain level were measured. After the clinical examination, the patients underwent a 30-second single-leg balance test on a force plate (AMTI Accugait, Watertown, MA, USA) at a sample frequency of $1,000 \mathrm{~Hz}$. The healthy persons underwent the same single-leg balance test as the ankle sprain patients.

\section{Test description}

Muscle strength: Maximum isometric muscle strength of the ankle plantar and dorsal flexors, invertors and evertors was measured with a handheld dynamometer (HOGGAN FET 2, in N) $[13,14]$ with the patient in a supine position (with a trunk-hip angle of 45 degrees) and the knee in extension. Handheld dynamometry has been shown to be a reliable method to measure ankle strength (ICC>0.77) [14]. The examiner holds the dynamometer stationary while the patient exerts maximal force against it. The foot was placed in a neutral position. Each test was repeated three times and the best performance was retained for analyses.

Joint mobility: The range of motion (ROM) of the ankle joint in the sagittal plane was measured with a manual goniometer (in degrees) [15] with the patient in a supine position (with a trunk-hip angle of 45 degrees). The patient was asked to bring the ankle actively into correct position, and thereafter the ankle was passively positioned in the maximum plantar flexion and dorsiflexion angles. The center of the goniometer was positioned just below the lateral malleolus, on the axis of rotation of the joint, in line with the lower leg midline and the fifth metatarsal. Dorsiflexion was measured in an extended knee position as well as with a $90^{\circ}$ bended-knee position.

Pain: Pain was evaluated using the Visual Analogue Scale (VAS) during rest and walking, ranging from 0 points (no pain) to 10 points (severe pain) [16].

Single-leg balance evaluation: Participants were instructed to remain as motionless as possible for 30 seconds while they were standing on the test leg on the force plate. They were instructed to look directly at a point on the wall $150 \mathrm{~cm}$ away. They were allowed to practice this position before the measurements started. Single-leg balance tests in stable and unstable $(6 \mathrm{~cm}$ Airex mat) conditions were assessed and the legs were examined alternately, each side three times. A measurement was stopped if the participant hopped on the weightbearing leg or touched down the non-weight-bearing leg.

\section{Data processing}

Each single-leg balance test lasted 30 seconds, of which only the middle 26 seconds were analyzed to avoid the "edge effect" of the test [17]. Single-leg balance was measured as the center of pressure (COP) excursion range in mediolateral (ML) and anteroposterior (AP) directions (in $\mathrm{mm}$ ), indicating the maximum deviation of the COP in the ML and AP axes. COP length was defined as the total length of the path movements during 26 seconds (in $\mathrm{mm}$ ), and the mean COP speed

Table 1. Baseline characteristics of ankle sprain patients and healthy controls.

\begin{tabular}{|c|c|c|c|}
\hline & Ankle sprain patients $(\mathrm{n}=48)$ & Healthy persons $(n=10)$ & $P$ value \\
\hline Side ankle sprain: Left/Right & $20 / 28$ & - & \\
\hline Grade ankle sprain: $1 / 2$ & $33 / 15$ & - & \\
\hline \multirow[t]{2}{*}{ Male/Female } & $26 / 22$ & $4 / 6$ & .415 \\
\hline & Mean \pm SD (range) & Mean \pm SD (range) & \\
\hline Age (years) & $34.3 \pm 9.7(18-55)$ & $30.1 \pm 4.7(21-36)$ & .189 \\
\hline BMI $\left(\mathrm{kg} / \mathrm{m}^{2}\right)$ & $24.2 \pm 2.9(18.4-29.8)$ & $23.0 \pm 2.3(20.0-27.4)$ & .218 \\
\hline Muscle strength $(\mathrm{N})$ & - & - & \\
\hline Dorsiflexion & $184.2 \pm 96.1(51.6-667.2)$ & - & \\
\hline Plantar flexion & $326.5 \pm 118.4(119.7-671.7)$ & - & \\
\hline Inversion & $85.0 \pm 39.2(14.0-177.9)$ & - & \\
\hline Eversion & $89.9 \pm 40.3(21.4-180.2)$ & - & \\
\hline Joint mobility $\left(^{\circ}\right)$ & - & - & \\
\hline Dorsiflexion (extended knee position) & $7.7 \pm 5.0(-5-20)$ & - & \\
\hline Dorsiflexion $\left(90^{\circ}\right.$ bended knee position) & $15.8 \pm 5.9(4-26)$ & - & \\
\hline Plantar flexion & $47.0 \pm 11.6(18-70)$ & - & \\
\hline VAS for pain (10 point scale) & - & - & \\
\hline Rest & $1.1 \pm 1.6(0.0-6.0)$ & - & \\
\hline Walking & $2.6 \pm 2.4(0.0-8.0)$ & - & \\
\hline
\end{tabular}


$(\mathrm{mm} / \mathrm{s})$ in $\mathrm{ML}$ and AP directions is the sum of the displacement scalars during 26 seconds.

For each participant, the best performance of three single-leg balance tests was included in data analysis. To do this, the standard score for normalization was calculated by taking the raw COP score minus the mean COP range of the population, divided by the COP standard deviation of the population. After normalization of the COP range in $\mathrm{ML}$ and $\mathrm{AP}$ directions, the best performance was chosen. The $\mathrm{COP}$ data were low-pass filtered at $10 \mathrm{~Hz}$ with a fourth-order and zerolag Butterworth filter [18]. Parameters were extracted with MATLAB and the open-source Biomechanical Tool Kit package for MATLAB [19].

\section{Sample size}

Given an expected correlation coefficient of 0.5 , a desired (onesided) probability level of 0.05 and a desired statistical power level of $80 \%$, the minimum sample size was 23 ankle sprain patients.

\section{Statistical analyses}

Analyses were performed using SPSS 18 (SPSS Inc., Chicago, IL, USA). The statistical review of the study was performed by a biomedical statistician. Descriptive statistics were used to present the study population (Age, BMI, Grade of Ankle Sprain and Pain).

Fisher's exact test was used to compare the proportion of participants in each group who managed to complete the 30 -second balance test and the ones who did not.

Only single-leg balance tests lasting 30 seconds were used for further statistical analyses. All balance parameters were checked for normality.

Spearman's correlation coefficient was used to check for associations between functional deficits of the injured ankle and an individual's balance performance. For that, muscle strength was normalized for body weight [20]. Correlations between 0.3 and 0.5 were considered moderate and a correlation of $\geq 0.5$ was considered strong [21]. In addition, we assessed differences in balance performance between ankle sprain patients and healthy persons using the Mann-Whitney test. To do so, we only used one ankle side per healthy subject (5 left ankles, 5 right ankles). $P$-values less than .050 were considered statistically significant.

\section{Results}

Forty-eight subacute ankle sprain patients (26 men, 22 women) with a mean age of $34.3( \pm 9.7)$ years and a mean BMI of $24.2( \pm 2.9) \mathrm{kg} /$ $\mathrm{m}^{2}$ and 10 healthy persons ( 4 men, 6 women) with a mean age of 30.1 $( \pm 4.7)$ years and a mean BMI of $23.0( \pm 2.3) \mathrm{kg} / \mathrm{m}^{2}$ participated in the study (Table 1). Muscle strength, joint mobility and pain level of the injured ankle were assessed during clinical evaluation, and results are shown in Table 1.

\section{Correlations between body function and balance in the ankle sprain patients}

Passive ROM, muscle strength in plantar and dorsiflexion and pain were not related to balance performance on the stable or the unstable surface. However, muscle strength in inversion and eversion correlated with COP range.

For the unstable surface, COP range in ML direction was moderately correlated to muscle strength in inversion $(\mathrm{R}=0.486, P=.002)$. Muscle strength and eversion were strongly correlated with CAP range in ML direction $(\mathrm{R}=0.568, P<.001)$ and moderately to COP range in AP direction $(\mathrm{R}=0.362, P=.026)$.

\section{Single-leg balance test}

All healthy persons managed to complete the single-leg balance test on the stable as well as on the unstable surface with both legs. Fortythree of the 48 patients (90\%) managed to complete the test on the stable surface $(P=.374)$ and no more than 38 patients $(79.1 \%)$ were able to finish this test on the unstable surface $(P=.125)$.

Compared to the healthy persons, ankle sprain patients presented a higher COP speed in AP direction $(P=.009)$ and larger COP length $(P=.034)$ for the stable surface (Table 2$)$. In addition, the COP range in AP direction was increased for the unstable surface in the ankle sprain patients $(P=.001$, Table 2$)$.

\section{Discussion}

This is the first study to investigate single-leg balance performance and assess its relation to an ankle sprain patient's body function (Grade I and II) during the subacute phase. This study showed that four weeks after a lateral ankle sprain, fewer patients were able to perform a 30-second single-leg balance test compared to healthy age-, sex- and BMImatched persons. The ankle sprain patients who were able to complete the balance test presented a larger COP range and speed in AP direction compared to healthy persons. Furthermore, ankle sprain patients showed lower muscle strength in inversion and eversion. Passive ROM and pain levels during walking were not related to balance performance.

Hertel et al.'s [8] results for COP speed (ML $2.9 \pm 0.7 \mathrm{~cm} / \mathrm{s}$, AP 3.4 $\pm 0.7 \mathrm{~cm} / \mathrm{s}$ ) and COP range (ML $2.5 \pm 0.6 \mathrm{~cm}, \mathrm{AP} 2.1 \pm 0.4 \mathrm{~cm}$ ) in

Table 2. Balance parameters of the injured side of the ankle sprain patient and both sides of the healthy persons.

\begin{tabular}{|c|c|c|c|c|c|}
\hline & \multicolumn{2}{|c|}{ Ankle sprain patients } & \multicolumn{2}{|c|}{ Healthy persons } & \multirow{2}{*}{$P$ value } \\
\hline & Mean \pm sd & range & Mean \pm sd & range & \\
\hline Stable surface & $(n=43)$ & - & $(\mathrm{n}=10)$ & - & - \\
\hline COP range ML (mm) & $27.1 \pm 5.7$ & $19.7-49.2$ & $23.7 \pm 4.6$ & $18.0-30.8$ & .084 \\
\hline COP range $\mathrm{AP}(\mathrm{mm})$ & $39.0 \pm 13.2$ & $15.1-84.4$ & $31.9 \pm 11.7$ & $18.1-52.6$ & .152 \\
\hline COP length (mm) & $1090.9 \pm 303.4$ & $490.6-1710.0$ & $890.4 \pm 253.1$ & $525.1-1486.1$ & .034 \\
\hline COP speed ML $(\mathrm{mm} / \mathrm{s})$ & $27.3 \pm 7.3$ & $14.3-43.2$ & $24.6 \pm 7.8$ & $14.4-44.1$ & .220 \\
\hline COP speed AP $(\mathrm{mm} / \mathrm{s})$ & $26.6 \pm 8.5$ & $9.7-50.5$ & $19.3 \pm 5.4$ & $11.3-28.4$ & .009 \\
\hline Unstable surface (AIREX) & $(\mathrm{n}=38)$ & - & $(\mathrm{n}=10)$ & - & - \\
\hline COP range ML (mm) & $32.0 \pm 7.7$ & $22.5-57.6$ & $28.9 \pm 4.5$ & $22.3-35.8$ & .286 \\
\hline COP range $\mathrm{AP}(\mathrm{mm})$ & $51.0 \pm 10.6$ & $31.8-78.4$ & $39.4 \pm 6.6$ & $28.4-47.0$ & .001 \\
\hline COP length (mm) & $1549.8 \pm 468.8$ & $522.6-2552.2$ & $1306.0 \pm 408.8$ & $861.7-2101.2$ & .110 \\
\hline COP speed ML $(\mathrm{mm} / \mathrm{s})$ & $40.9 \pm 13.2$ & $13.0-65.8$ & $33.6 \pm 12.1$ & $21.2-58.3$ & .060 \\
\hline COP speed AP $(\mathrm{mm} / \mathrm{s})$ & $35.6 \pm 11.6$ & $12.7-69.2$ & $31.0 \pm 8.1$ & $21.0-44.9$ & .232 \\
\hline
\end{tabular}


patients four weeks post injury were comparable to our results for the stable surface. They found that the COP speed in both directions at four weeks improved significantly compared to one day and two weeks after injury. For the COP range, they only found an improvement in ML direction compared to one day after the sprain [8]. Furthermore, they found a difference for COP speed in ML direction when they compared the injured and non-injured side. However, using the non-injured leg as a reference level is not recommended due to changes in this side as well; therefore, comparisons with healthy age-matched persons might reveal even larger differences [10]. In addition, more challenging tasks, like single-leg balancing on an unstable surface, resulted in larger and faster COP excursions because all sensory sensors and sensory integration are stimulated [22]. Our data showed a larger COP range only in AP direction for the unstable surface, and an increased COP speed in AP direction for the stable surface was found. If the velocity of COP increases, it becomes more difficult for the body to adequately compensate for the excursions and keep the COP within the base of support [8].

Nilsson et al. [23] found that clinical strength measures (repetitions of rising on toes and heels) in the sagittal plane were correlated to the ability to perform a single-leg balance test. They did not study muscle strength in the frontal plane, [23] but we found that increased muscle strength in inversion and eversion directions (frontal plane) was strongly correlated to a larger COP range in ML direction on the unstable surface. Because the patients had an inversion trauma, it is likely there is a deficit in the frontal plane. Besides strength, full ROM of the ankle is thought to be necessary to perform daily life activities optimally [23]. Nevertheless, our results did not show a relation between decreased ROM and balance performance. Deficits in ROM might have a larger influence on tasks requiring greater ROM such as walking, running and jumping.

The results showed that patients only had very moderate pain during rest (mean \pm sd $1.1 \pm 1.6)$ and walking $(2.6 \pm 2.4)$ four weeks after the sprain. No correlation between pain and balance performance could be identified. In contrast, previous studies showed that pain stimulation has a negative influence on postural balance in healthy subjects in a bipedal stance [24,25]. Interestingly, Corbeil et al. [25] showed that pain effects only appeared when a threshold was attained; a weak pain intensity (3 out of 10) did not influence COP performance except for COP range in AP direction. Because our patients had a low degree of pain, the tests were performed in a single-leg stance and the pain stimulation was not continuous. As compared to the tests in healthy subjects, this might explain the different findings.

The strengths of our study design are as follows: First, no exercise therapy was given in the acute phase to study the natural recovery of the injury. Second, we did not include patients aged above 50 because increased age is a known risk factor for decreased balance performance due to musculoskeletal weakness and a weight shift $[23,26]$. Third, for comparisons, a healthy age-, sex- and BMI-matched control group was included. Also, patients with a BMI over 30 were excluded, because obesity is a well-known factor influencing balance performance [27]. Finally, other studies revealed deficits in postural control in not only the injured but also the uninjured leg of ankle sprain patients compared with healthy persons $[9,12]$. The authors of these studies think that these deficits may be the result of proprioceptive deficits of the ankle ligaments, impaired strength of the muscles and/or mechanical instability of the ankle joint, which results in larger COP excursions $[8,28]$. The time-point postural control deficits are resolved between the uninjured limb (on average 7 days) and the injured limb (at least
4 weeks after injury) [9]. To avoid any bias, for comparisons, a healthy control group should be included because using the uninjured limb may lead to inappropriate conclusions, and a hasty return to work and sport activities and might increase the risk of a recurrent sprain.

A limitation of this study is that muscle strength was measured with a handheld dynamometer. If the patient is strong, he or she might be able to overpower the assessor. In this situation, the tested person would not be generating an isometric contraction, [13] which might lead to an underestimation of generated power. Therefore, the use of a handheld dynamometer with an external belt-fixation could have been more appropriate. A second limitation might be that the stable surface condition is not challenging enough to the postural control systems of these young patients. Having subjects close their eyes would make it more challenging in addition to the unstable surface but could decrease the number of participants able to perform the task. Third, the small size of the control group might affect the statistical power of the study; however, we matched both groups for age, sex and BMI to reduce this.

Balance and coordination training are common components of rehabilitation programs to treat patients with a (sub)acute ankle sprain and chronic ankle instability [7]. These programs often comprise socalled proprioceptive exercises on unstable surfaces, such as a wobble board, foam or ankle disc [29,30]. It is assumed that single-leg standing on these unstable surfaces stimulates the use of proprioceptive signals from around the ankle and in this way is beneficial for ankle instability [29]. These rehabilitation programs have been shown to be effective in reducing the number of recurrent injuries in patients with an ankle sprain $[11,30]$. Based on our results, adding frontal plane ankle strength exercises to standard treatment and balance exercises should be studied in future research.

\section{Conclusion}

In conclusion, ankle sprain patients still have disturbed balance performance and a decreased ability to fulfill a 30-second singleleg balance test four weeks after the ankle sprain. The larger COP excursions and higher speed in AP direction represent an inability to limit excessive center of mass movement during single-leg balance tests. Muscle strength in inversion and eversion was negatively related to these COP excursions in ML directions for unstable conditions. Therefore, it might be useful to add more specific strength exercises in the frontal plane in current treatment protocols.

\section{Author contributions}

Jean-Luc Ziltener and Lara Allet contributed to study design; Ilona M. Punt, Stephane Armand and Lara Allet contributed to data acquisition and data analysis; Ilona M. Punt, Stephane Armand, JeanLuc Ziltener and Lara Allet contributed to the data interpretation and writing the article which was approved by all authors.

\section{Acknowledgements}

This work was supported by the Centre de Recherche Clinique (CRC) grant (PRD 12-I-8, Switzerland) and Office Fédéral du Sport (OFSPO, Switzerland).

\section{References}

1. Fong DT, Hong Y, Chan LK, Yung PS, Chan KM (2007) A systematic review on ankle injury and ankle sprain in sports. Sports Med 37: 73-94. [Crossref]

2. van Rijn RM, van Os AG, Bernsen R, Luijsterburg PA, Koes BW, Bierma-Zeinstra S (2008) What is the clinical course of acute ankle sprains? A systematic literature review. The American journal of medicine 121: 324-331. [Crossref] 
3. Nazarenko A, Beltran LS, Bencardino JT (2013) Imaging evaluation of traumatic ligamentous injuries of the ankle and foot Radiologic Clinics of North America 51: 455-478 [Crossref]

4. McKeon PO, Hertel J (2008) Systematic review of postural control and lateral ankle instability, part I: can deficits be detected with instrumented testing Journal of athletic training 43: 293. [Crossref]

5. Genthon N, Bouvat E, Banihachemi J, Bergeau J, Abdellaoui A, et al. (2010) Lateral ankle sprain alters postural control in bipedal stance-part 1: restoration over the 30 days following the injury Scandinavian journal of medicine \& science in sports 20: 247-254. [Crossref]

6. Rozzi S, Lephart S, Sterner R, Kuligowski L (1999) Balance training for persons with functionally unstable ankles The Journal of orthopaedic and sports physical therapy 29: 478-486. [Crossref]

7. Wikstrom E, Naik S, Lodha N, Cauraugh J (2009) Balance capabilities after lateral ankle trauma and intervention: a meta-analysis Medicine Science in Sports Exercise 41: 1287. [Crossref]

8. Hertel J, Buckley W, Denegar CR (2001) Serial testing of postural control after acute lateral ankle sprain. Journal of athletic training 36: 363. [Crossref]

9. Evans T, Hertel J, Sebastianelli W (2004) Bilateral deficits in postural control following lateral ankle sprain Foot \& ankle international 25: 833-839. [Crossref]

10. Holme E, Magnusson S, Becher K, Bieler T, Aagaard P, et al. (1999) The effect of supervised rehabilitation on strength, postural sway, position sense and re-injury risk after acute ankle ligament sprain Scandinavian journal of medicine \& science in sports 9: 104-109. [Crossref]

11. McKeon PO, Hertel J (2008) Systematic review of postural control and lateral ankle instability, part II: is balance training clinically effective Journal of athletic training 43: 305. [Crossref]

12. Wikstrom EA, Naik S, Lodha N, Cauraugh JH (2010) Bilateral balance impairments after lateral ankle trauma: a systematic review and meta-analysis Gait \& posture 31: 407-414. [Crossref]

13. Kelln BM, McKeon PO, Gontkof LM, Hertel J (2008) Hand-held dynamometry: reliability of lower extremity muscle testing in healthy, physically active, young adults Journal of sport rehabilitation 17: 160. [Crossref]

14. Spink MJ, Fotoohabadi MR, Menz HB(2009) Foot and ankle strength assessment using hand-held dynamometry: reliability and age-related differences Gerontology 56 : 525-532. [Crossref]

15. Elveru RA, Rothstein JM, Lamb RL (1988) Goniometric reliability in a clinical setting subtalar and ankle joint measurements Physical Therapy 68: 672-677. [Crossref]
16. Bijur PE, Silver W, Gallagher EJ (2001) Reliability of the visual analog scale for measurement of acute pain. Academic Emergency Medicine 8: 1153-1157. [Crossref]

17. Isakov E, Mizrahi J (1997) Is balance impaired by recurrent sprained ankle? British journal of sports medicine 31: 65-67. [Crossref]

18. Duarte M, Zatsiorsky VM (2002) Effects of body lean and visual information on the equilibrium maintenance during stance Experimental Brain Research1 46: 60-69. [Crossref]

19. Barre A, Armand S (2014) Biomechanical ToolKit: Open-source framework to visualize and process biomechanical data Comput Methods Programs Biomed 114: 8087. [Crossref]

20. Jaric S, Muscle strength testing: use of normalisation for body size (2002) Sports Med 32:615-631 321002 [pii]:321002 [pii]]. [Crossref]

21. Cohen J (1988) Statistical power analysis for the behavioral sciences

22. Hazime FA, Allard P, Ide MR, Siqueira CM, Amorim CF, et al. (2012) Postural control under visual and proprioceptive perturbations during double and single limb stances: Insights for balance training Journal of Bodywork and Movement Therapies 16: 224229. [Crossref]

23. Nilsson G, Ageberg E, Ekdahl C, Eneroth M (2006) Balance in single-limb stance after surgically treated ankle fractures: a 14-month follow-up BMC musculoskeletal disorders 7: 35 [Crossref]

24. Blouin J-S, Corbeil P, Teasdale N (2003) Postural stability is altered by the stimulation of pain but not warm receptors in humans BMC musculoskeletal disorders 4: 23 . [Crossref]

25. Corbeil P, Blouin J-S, Teasdale N (2004) Effects of intensity and locus of painful stimulation on postural stability Pain 108: 43-50. [Crossref]

26. Jonsson E, Seiger $\AA$, Hirschfeld H (2004) One-leg stance in healthy young and elderly adults: a measure of postural steadiness? Clinical biomechanics 19: 688-694. [Crossref]

27. Hue O, Simoneau M, Marcotte J, et al. (2007) Body weight is a strong predictor of postural stability. Gait \& posture 26: 32-38. [Crossref]

28. Ross SE, Guskiewicz KM (2004) Examination of static and dynamic postural stability in individuals with functionally stable and unstable ankles Clinical Journal of Sport Medicine 14: 332-338. [Crossref]

29. Kiers H, Brumagne S, Van Dieen J, van der Wees P, Vanhees L (2012) Ankle proprioception is not targeted by exercises on an unstable surface European journal of applied physiology 112: 1577-1585. [Crossref]

30. Munn J, Sullivan SJ, Schneiders AG (2010) Evidence of sensorimotor deficits in functional ankle instability: a systematic review with meta-analysis Journal of Science and Medicine in Sport 13: 2-12. [Crossref]

Copyright: (C2017 Punt IM. This is an open-access article distributed under the terms of the Creative Commons Attribution License, which permits unrestricted use, distribution, and reproduction in any medium, provided the original author and source are credited. 